Clemson University

TigerPrints

6-2009

Enhancing research and practice in early childhood through formative and design experiments

Barbara A. Bradley

David Reinking

Follow this and additional works at: https://tigerprints.clemson.edu/eugene_pubs

Part of the Education Commons 


\section{Enhancing research and practice in early childhood through formative and design experiments}

\section{Barbara A. Bradley \& David Reinking}

To cite this article: Barbara A. Bradley \& David Reinking (2011) Enhancing research and practice in early childhood through formative and design experiments, Early Child Development and Care, 181:3, 305-319, DOI: $10.1080 / 03004430903357894$

To link to this article: https://doi.org/10.1080/03004430903357894

曲 Published online: 04 Jan 2010.

Submit your article to this journal $๘$

III Article views: 1296

Q View related articles $\sqsubset$

4 Citing articles: 8 View citing articles 


\title{
Enhancing research and practice in early childhood through formative and design experiments
}

\author{
Barbara A. Bradley ${ }^{\mathrm{a} *}$ and David Reinking ${ }^{\mathrm{b}}$ \\ ${ }^{a}$ Department of Curriculum and Teaching, University of Kansas, 443 J.R. Pearson Hall, 1122 \\ West Campus Road, Lawrence, KS 66045, USA; ${ }^{b}$ Eugene T. Moore School of Education, \\ Clemson University, 418 Tillman Hall, Clemson, SC 29634, USA
}

(Received 30 June 2009; final version received 17 September 2009)

\begin{abstract}
This article describes formative and design experiments and how they can advance research and instructional practices in early childhood education. We argue that this relatively new approach to education research closes the gap between research and practice, and it addresses limitations that have been identified in early childhood research. We provide examples of this approach's potential benefits, trace its origins, present its defining characteristics, illustrate a representative framework for conducting a formative experiment using an example from our own work and we argue that formative and design experiments introduce useful new metaphors into early childhood research.
\end{abstract}

Keywords: formative experiments; design experiments; mixed methods; pragmatism

Well-designed and well-implemented early childhood programmes clearly benefit young children (Barnett, 1995; Gormley, Gayer, Phillips, \& Dawson, 2005). However, research indicates that most state-funded programmes in the USA are mediocre in quality based on measures of global classroom process (Clifford et al., 2005). For a variety of typically unspecified reasons, early childhood teachers have difficulty implementing high-quality instructional practices that benefit young children. Yet, despite this lack of quality and the difficulty that teachers have in achieving it, 'many Americans seem to believe that work in education requires common sense more than it does the sort of disciplined knowledge and skill that enable work in other fields' (Ball \& Forzani, 2007, p. 529). This belief is, of course, unfounded. Systematic and disciplined inquiry into real problems in authentic classrooms is vital to developing workable solutions to support teachers if they are to implement instructional practices that benefit children. However, widely used research methodologies with conventional quantitative and qualitative paradigms have for many years done little to close the often-lamented gap between research and practice. For example, Robert Ebel, a president of the American Educational Research Association, stated, 'education is not in need of research to find out how it works. It is in need of creative invention to make it work better' (1982, p. 18, emphasis in original). Some argue that little has been accomplished in the field of education in the years since Ebel made that observation (see Lagemann, 2000).

*Corresponding author. Email: barbarab@ku.edu 
Formative experiments and design experiments represent an approach to education research that aims to close the gap between research and practice and thus to contribute more directly to improving instructional practice. Specifically, formative and design experiments aim to determine how valued pedagogical goals might be achieved in the inherently complex and dynamic environments of real classrooms by identifying factors that enhance or inhibit the effectiveness of a research- or theory-based instructional intervention. Further, the aim of formative and design experiments, through iterative cycles of data collection, is to modify the instructional intervention or the environment, in light of the factors identified, ultimately towards achieving a valued goal. Although we use the terms formative experiments and design experiments together, there are subtle differences between the approaches. For example, researchers conducting formative experiments tend to focus on an instructional intervention and a pedagogical goal, whereas researchers conducting design experiments typically emphasise broader goals and theory development (Reinking \& Bradley, 2004). However, for the sake of this article, which is aimed at introducing this methodological approach, these differences are negligible.

We believe that formative and design experiments are particularly well suited for conducting research in early childhood classrooms and addressing the challenges of implementing high-quality instruction in diverse early childhood settings. Specifically, formative and design experiments address important gaps in knowledge about early childhood programmes. For example, Takanishi and Bogard (2007) argued that research in early childhood education needs to address: (1) a better understanding of children from diverse backgrounds and their early childhood experiences; (2) a better understanding of teacher-child interactions in relation to desired outcomes; (3) a consideration of a broader range of outcomes for young children; (4) a consideration of a broader representation of disciplines to better understand early childhood programmes; and (5) '[a reconsideration of] how the mutual, two-directional, synergistic relationships between research and practice take place' (p. 42). In this article we introduce formative and design experiments as an approach to research that can address such issues.

\section{How do conventional research methodologies inform early childhood practice?}

Research in early childhood education, as in other areas of education, is typically categorised as quantitative and qualitative research. Researchers who engage in quantitative studies often conduct controlled experiments to determine what works best on average. For example, in the Chicago School Readiness Project (CSRP; Raver et al., 2008), researchers used a cluster randomised control trial design 'to test whether CSRP's intervention services had an impact on teachers' management of children's disruptive behaviour and on teachers' ability to foster an emotionally positive classroom climate' and 'to test whether this package of classroom-based services reduces children's risk of behavioural difficulty and increases their changes of school readiness' (p. 13). On the other hand, qualitative researchers conduct naturalistic studies to document the subtle complexities of classroom experience. That is, researchers using a naturalistic approach in early childhood might explore instructional practices in a classroom focusing on the interpretation and meaning the intervention has for children and teachers. For example, in her qualitative case study, Ryan (2004) reported how two preschool teachers responded to a mandate that they implement particularly early in the childhood curriculum. 
Although both methodologies provide useful data that might inform practice, both approaches, like all methodologies, have their limitations. For example, controlled experiments typically do not consider the complex and dynamic nature of classrooms; rather, they attempt to control for the complexities of classrooms or minimise their effect on a few specific outcomes that are the focus of an investigation. Therefore, such research does not necessarily help teachers to understand how instructional practices might be effectively implemented within the context or constraints of their own classrooms. Although naturalistic studies do document the complexities of the classroom environment, typically they do not address how a teacher might manage those factors to implement effectively and efficiently an instructional intervention towards achieving a valued instructional goal.

Formative and design experiments, however, directly address these limitations. Unlike experimental or naturalistic studies of instructional interventions, they not only take into consideration the contextual complexities of a classroom, they aim to reveal factors that enhance or inhibit an intervention in order to adapt instructional practices in response to those complexities (Reinking \& Bradley, 2008). Further, the purpose of formative and design experiments is to generate research that is more directly relevant to practice, to inform theory development and to identify factors that might be investigated through conventional experimental or naturalistic approaches (Reinking \& Bradley, 2004).

\section{Why formative and design experiments are well suited for informing instructional practices in early childhood classrooms}

In this section we highlight three reasons that formative and design experiments are particularly well suited to conducting research in early childhood classrooms. First, this methodological approach recognises and explores the complexities of classroom environments and the dynamic interactions among diverse variables that teaching certain children in a specific context inherently entails. Secondly, researchers conducting formative and design experiments take a collaborative stance when working with teachers in classrooms. Finally, the iterative cycles of data collection, interpretations and adaptations of an instructional intervention, which is at the heart of this approach, support the professional development of teachers. In the remainder of this section, we elaborate on each of these reasons.

\section{Classroom complexity}

Early childhood classrooms are complex environments. That complexity is compounded in the USA and other countries where there is much diversity in the orientations, emphases and logistical operations of early childhood programmes. For example, there are many differences among early childhood settings based on: (1) hours of attendance (e.g. half-day, full-day or extended care); (2) how children are grouped (e.g. same age, mixed age); (3) location (e.g. home daycare, centre-based, school-based, church-based); (4) whether the funding sources are public or private; (5) availability of materials and other resources; (6) curriculum and philosophy (e.g. child-centred, teacher-directed, curriculum-driven); (7) ratio of children-to-teachers; (8) teachers' level of education and opportunities for professional development; and (9) children's demographic characteristics (e.g. culturally and linguistic background and family's socio-economic status). Any one of these factors, and often some 
combination of them, may affect the effectiveness, efficiency and appeal of any instructional intervention regardless of any positive effects it has been shown to produce from conventional quantitative or qualitative research.

Researchers, who conduct formative and design experiments, acknowledge such diversity as an essential reality of conducting education research. They believe that research methodologies attempting to neutralise or to ignore such variability, as is typically the case for quantitative approaches, or that simply describe that variability towards no particular goal, as is typically the case with qualitative approaches, do not speak directly to instructional practice. Instead, researchers who conduct formative and design experiments strive to identify factors within authentic and diverse classroom environments that enhance or inhibit an instructional intervention's effectiveness in reaching a well-specified pedagogical goal, and then they modify the intervention to offset inhibiting factors and to capitalise on those that enhance its effects. It is the identification of such factors and workable modifications, we believe, that may provide early childhood teachers with a more effective means of evaluating and implementing instructional recommendations based on their own circumstances and the needs of their children. That is, we believe that by identifying and presenting such factors and workable modifications, other early childhood teachers in similar circumstances will be better able to critically evaluate and implement an intervention within their own classroom context, and, thus, begin to close the gap between research and practice. Firestone (1993) refers to this as case-to-case generalisations. In short, we believe early childhood teachers have the potential to implement high-quality programmes, but such programmes have not been realised across a large number of sites, due, in part, to the many differences among early childhood programmes, teachers, policies and resources (Kirp, 2007; Takanishi \& Bogard, 2007), that have not been considered when planning, conducting and interpreting research. In short, formative and design experiments recognise that there are a host of interacting factors that not only shape what is possible, but what is needed and desirable (Brown, 1992; Dillon, O’Brien, \& Heilman, 2000).

\section{Collaborative}

Formative and design experiments represent an approach to research that may be particularly appealing to teachers because it invites teachers to enter into a collaborative relationship with researchers. Researchers respect teachers' autonomy in the context of an investigation and form a mutually respectful relationship with them (Lenski, 2001). That relationship is particularly important in research conducted in early childhood education. For example, Takanishi and Bogard (2007) stated, 'translating research into practice obviously requires mutually respectful relationships between researchers and practitioners working in authentic partnerships. Unfortunately, such relationships have not been the norm in the history of child development research' (p. 44). However, this collaboration does not necessarily mean that teachers and researchers share equal roles and responsibilities for conducting the research. Rather, we believe that formative and design experiments align with what Cole and Knowles (1993) described as a teacher development partnership. Specifically, they stated:

True collaboration is more likely to result when the aim is not for equal involvement in all aspects of the research; but, rather, for negotiated and mutually agreed upon 
involvement where strengths and available time commitments to process are honored. (p. 486, emphasis in original)

Thus, researchers conducting a formative and design experiment, in addition to developing a professionally productive relationship with teachers, rely on teachers' knowledge and expertise to assist in the identification of factors that can enhance or inhibit an instructional intervention's effectiveness, as well as to assist in developing realistic adaptations that might be made to the intervention and the classroom environment.

Identifying factors and adapting an intervention and the environment in which it occurs may be particularly appealing to teachers because it involves them in reflective teaching. That is, researchers conducting formative and design experiments often engage in several forms of experimentation in which reflective practitioners engage. For example, in his seminal work, Schön (1987) described how reflective practitioners engaged in: (1) exploratory experimentation, which is action to see what happens; (2) move-testing experimentation, which is in understanding if an action supports or interferes with an objective or goal, and determining if there are any unexpected consequences; and (3) hypothesis testing, which is similar to more formal experimentation. Researchers using formative and design experiments engage in such experimentation guided by rigorous data collection and analysis. This distinctive perspective is important because as Eisenhart and Borko (1993) suggested, 'researchers see the significance of research in terms of its implications for understanding far-ranging repercussions, predicting and improving the future, or getting tenure, whereas teachers usually want research results to bear directly on their classroom practice' (p. 79).

\section{Professional development}

Instructional interventions that are the object of study in formative and design experiments are often aimed at changing teachers' instructional practice and transforming classroom environments. Thus, they sometimes confront teachers' beliefs and actions. The collaboration between a researcher and a teacher in a formative and design experiment may provide an opportunity for professional development for a teacher, but also for a researcher whose dearly held theories of instruction may be undermined by the realities of classroom practice. Formative and design experiments, then, may facilitate simultaneously the professional development of teachers and researchers. And, this approach has much potential to do so without threatening either party's sense of professionalism. However, researchers using this approach need to be particularly sensitive to issues that teachers may encounter when asked to consider changes in how they teach and how they organise and manage instruction.

There are several relevant issues related to professional development and how it may enhance collaboration between teachers and researchers. First, teachers' attitudes and beliefs about teaching and research may influence their ability to adopt new educational practices. For example, many early childhood teachers tend to believe that it is more important to facilitate the socio-emotional development of young children than their oral language, literacy and maths skills (Kowalski, Pretti-Frontczak, \& Johnson, 2001). Therefore, when encouraging teachers to promote oral language, literacy or maths skills, it may be important to emphasise that children's socio-emotional development does not suffer if these more academically oriented activities are 
promoted (Kowalski et al., 2001). In fact, the literature in early childhood education supports that conclusion. That is, asking teachers to be more sensitive and more responsive to children's needs not only supports children's socio-emotional development but also enhances their oral language development (Burchinal, Cryer, Clifford, \& Howes, 2002; Whitebrook, Howes, \& Phillips, 1989). Thus, formative and design experiments provide a context of mutual support and collaboration towards achieving a valued goal in which teachers may be more inclined to reflect upon and adopt such perspectives into their teaching.

Another issue is that contextual factors, such as the curriculum, and the support and time available for engaging in reflective practice, influence teachers' abilities and desire to adopt new educational practices. Thus, in addition to providing early childhood teachers with guidelines and strategies for implementing an educational practice (Hughes \& Westgate, 1997), contextual factors must be considered. That is, research suggests that an educational practice is more likely to succeed when it is ecologically valid within the environmental constraints of a classroom (Bronfenbrenner, 1979) and it is more likely to be implemented and maintained when it is congruent with teachers' educational goals or philosophies (see Schwartz \& Carta, 1996). Formative and design experiments provide a viable means first for understanding the extent to which that congruity is important and workable, and thus authentically generating that necessary congruity.

Teachers also need time and opportunity to reflect on their knowledge and experience in relation to research (Malouf \& Schiller, 1995). Reflection is not only an important component of effective teaching (Schön, 1987), but reflective practice is necessary because teaching is 'complex, situation-specific, and dilemma-ridden' (Sparks-Langer \& Colton, 1991, p. 37). Reflective practice that leads to effective teaching can be facilitated by allowing teachers opportunities to share their ideas and thoughts, and by creating opportunities for teachers to question their beliefs (Klein \& Gilkerson, 2000). That is, engaging in reflective practice through participation in ongoing discussions with other teachers and researchers as part of a longitudinal study common in formative and design experiments may further contribute to effective practices (Cady, Schaak Distad, \& Germundsen, 1998).

\section{Where do formative and design experiments come from and what is the status of this approach?}

The rationale and need for formative and design experiments arose independently from diverse sources, suggesting that this approach addresses a fundamental dissatisfaction with the limitations of more conventional approaches to education research (see Reinking \& Bradley, 2008 for a detailed history). Jacob (1992) traced the origins of formative experiments to a neo-Vygotskian perspective that acknowledged how social factors affected psychological phenomenon. Among researchers who currently conduct formative or design experiments, the work of Ann Brown (1992), a cognitive psychologist who studied metacognitive aspects of reading comprehension, is widely considered to be seminal. She moved towards what she called design research when she found it difficult to implement in classrooms an instructional intervention that grew out of her quantitative experiments under controlled conditions in her laboratory. As a prominent experimentalist who saw the limitations of using experimental methods in classroom research, she gave credence to the need for more qualitative approaches that might be the basis of an engineering science of education. 
Even earlier, Moll and Diaz (1987), who used qualitative research methods to study how Latino youth in the American Southwest possessed linguistic skills in Spanish that were not tapped in helping them achieve academically in Englishspeaking schools, argued that bringing about positive change was the goal of education research. Although they did not use the terms formative experiment or design experiment, the dominant themes of their work are consistent with this approach. Likewise, Eisenhart and Borko (1993), the first an anthropologist and the latter an experimental psychologist, argued that to conduct meaningful research, "classroom researchers should try to design research studies that accommodate the complexity and distinctiveness of classroom life' (p. 131). More recently, Pressley, Graham, and Harris (2006) declared the status of intervention research as inadequate and called for classroom research that employs multiple theoretical perspectives, attends to process variables that explain how and why interventions work or do not work and 'the rich array of outcomes and relationships that might be impacted by the intervention' (p. 6), accommodates the multiple interacting factors that determine success or lack of success in various environments, and better communicates results in a form useful to practitioners. Formative and design experiments embody these characteristics.

As these few examples illustrate, formative and design experiments gain legitimacy because the rationale and need for this methodological alternative has emerged among mainstream researchers who come from different perspectives and methodological traditions, but who have been dissatisfied to some degree with the limitations of conventional methodologies when applied to classroom research. Notably this methodological approach has originated within the field of education unlike other research methodologies that have been borrowed or adapted from other disciplines and that Lagemann (2000) has argued accounts for much of the troubled history of education research.

There are other signs that formative and design experiments are entering the mainstream of education research and are being used increasingly among classroom researchers. For example, three highly regarded research journals have devoted themed issues to design research: Educational Researcher (2003, Vol. 32, No. 1), Educational Psychologist (2004, Vol. 39, No. 4) and the Journal of Learning Sciences (2004, Vol. 13, No. 1); the latter specifically seeks to publish studies using this methodological approach. Likewise, the edited books entitled Educational Design Research (van den Akker, Gravemeijer, McKenney, \& Nieveen, 2006) and Handbook of Design Research Methods in Education (Kelly, Lesh, \& Baek, 2008) testify to the international appeal of this methodological approach.

However, unfortunately in our view, researchers in early childhood settings have not adopted the perspectives and methods associated with formative and design experiments. We have found few published studies in the literature of early childhood research that have employed formative and design experiments (Neuman, 1999) or similar approaches using different terminology (Edwards, 2007). This lack of examples is particularly unfortunate because we believe there is a gap between research and practice in early childhood education. Further, as we argued previously in this article, the characteristics of formative and design experiments seem well suited to address calls for the type of research that is needed to address gaps in the field's base of knowledge (Takanishi \& Bogard, 2007). Thus, in the following sections, we describe formative and design experiments in more detail. 


\section{Defining characteristics of formative and design experiments}

Although there are differences in how researchers who use formative and design experiments conceptualise, implement and describe their work, there is some convergence among researchers about the defining characteristics of this approach. The following defining characteristics are drawn from a variety of sources, but significantly from Cobb, Confrey, diSessa, Lehrer, and Schauble (2003):

(1) Formative and design experiments are intervention-centred and conducted in authentic educational settings. An instructional intervention and its effects are always the central object of study. It may be an innovative new intervention or an existing well-researched one. It may entail a single well-defined instructional activity or a coherent set of activities aimed at accomplishing a pedagogical goal. However, importantly, the way the intervention is implemented is subject to modification and adaptation based on data gathered and collected during the investigation. Thus, the way the intervention is implemented at the end of an investigation may be quite different from the outset.

(2) Theory plays a central role in conducting a formative or design experiment. It provides the rationale for the intervention and its implementation, and a major goal of a study may be to test whether a theory can stand up to the realities of classrooms. As Cobb et al. (2003) stated theories are put in 'harm's way' and they 'must do real work' (p. 10) in order to refine or develop theories that address 'both the process of learning and the means that are designed to support learning' (p. 9, emphasis in original). They argue that studies may be guided by grand theories of learning but an aim is to develop more humble theories grounded in authentic pedagogy and that consequently are closer to instructional practice.

(3) Formative and design experiments are goal-oriented, investigating concretely how to improve instruction and learning in authentic educational settings. Therefore, central to the methodology is specifying a clearly articulated pedagogical goal and explaining why it is valued and important. Further, the pedagogical goal becomes the central reference point for collecting and analysing data, for identifying factors that enhance or inhibit the implementation of an intervention, for making modifications and for determining if and to what extent progress has been made towards achieving that goal.

(4) Formative and design experiments involve an iterative process of data collection and data-driven adaptation of the instructional intervention or educational environment. Further, unlike researchers who use conventional experiments to study effectiveness of an instructional intervention, researchers who implement formative and design experiments are not concerned with fidelity because they approach a study with the assumption that changes will inevitably be made to an intervention in response to data indicating what is or is not working. This iterative process involves systematic and rigorous data collection, analysis and modifications, which may occur within a classroom, across classrooms or across studies (Gravemeijer \& Cobb, 2006).

(5) Researchers who conduct formative and design experiments recognise that contextual factors influence an instructional intervention, and, likewise, the intervention may influence or transform the educational environment. Although it is typically expected that an educational environment will be transformed in a positive manner, the intervention may produce unintended or 
unanticipated consequences. Consequently, researchers collect data with that possibility in mind and with the awareness that consequences, both positive and negative, may contribute to theory building or lead to other findings that have implications for subsequent research.

(6) Rather than being guided by a single method of collecting and analysing data, researchers conducting formative or design experiments may employ diverse methods for collecting and analysing data, as long as they can justify how their methods further the understanding and implementation of the intervention or the development or refinement of theory. However, because contextual factors and variations are of concern, it is essential that qualitative data be collected. Therefore, researchers who conduct formative and design experiments are often likely to use mixed methods and thus should be aware of the issues and standards related to that methodology (e.g. see Johnson \& Onwuegbuzie, 2004; see also Li, Marquart, \& Zercher, 2000 for using mixed methods in early childhood research). Simply put, formative and design experiments are methodologically inclusive and flexible.

(7) Philosophically, researchers who conduct formative and design experiments are more likely aligned with the philosophy of pragmatism, which has been discussed as a useful paradigm for education research (Cherryholmes, 1993; Dillon et al., 2000), than with epistemological and ontological issues underlying research. Pragmatism fits this methodological approach because it allows for: (i) more flexibility in methods and analysis; (ii) focus on useful ends; and (iii) democratic involvement of stakeholders.

\section{A representative framework for conducting a formative experiment}

Because a comprehensive overview of frameworks used to conduct formative and design experiments would be lengthy, we offer here a representative example that has been used in several published formative experiments (e.g. Ivey \& Broaddus, 2007; Lenski, 2001; Reinking \& Watkins, 2000; see Reinking \& Bradley, 2008 for a more comprehensive summary of frameworks) and that has guided a study we conducted in a preschool classroom (Bradley \& Reinking, in press). Our intent is that readers who are not intimately familiar with formative and design experiments might get a glimpse into the process of conceptualising, planning and reporting a formative experiment in general and in early childhood education in particular. The framework comprises addressing the following six questions:

(1) What is the pedagogical goal to be investigated, why is that goal valued and important and what theory and previous empirical work speaks to accomplishing that goal instructionally? The pedagogical goal in our study was to increase the quality and quantity of language interactions between children and preschool teachers in order to facilitate children's oral language skills. That goal, we argued, is important because previous research has indicated that early childhood classrooms tend to be relatively poor language learning environments (Helburn, 1995). Most talk tends to be related to routine matters (Dunn, 1993; Kontos \& Wilcox-Herzog, 1997), and teachers rarely expect children to participate in extended conversations that involve decontextualised or cognitively challenging talk (Tizard \& Hughes, 1984). Yet, research shows that rich language interactions facilitate children's oral language development 
(Snow, 1983) as well as early literacy skills (Dickinson \& Tabors, 2001; NICHD, 2005; Storch \& Whitehurst, 2002).

(2) What instructional intervention, consistent with a guiding theory, has the potential to achieve the pedagogical goal and why? In our study, the intervention involved the use of semantically contingent talk (Snow, 1983) and decontextualised questions (Dickinson \& Smith, 1994; Snow, 1983, 1991) during routine preschool activities that created opportunities for teachers to engage children in language interactions. Specifically, the teachers with whom we worked were encouraged to use semantically contingent responses and to ask decontextualised questions, as appropriate, during book sharing (Beck \& McKeown, 2001; Wasik, Bond, \& Hindman, 2006), structured group activities (Girolametto, Weitzman, van Lieshout, \& Duff, 2000), and mealtimes (Cote, 2001).

(3) What factors enhance or inhibit the effectiveness, efficiency and appeal of the instructional intervention in regard to achieving the educational goal? Whereas the previous two questions help to conceptualise a formative experiment, this question and those that follow inform data collection, analysis and interpretation. Basically, the aim of these questions is to: (i) determine what works, what does not and why; (ii) understand what accommodation might be made to the instructional intervention or the educational environment so that the educational goal might be achieved; and (iii) develop and/or refine theoretical understandings of instruction and learning. For example, in our study, mealtime conversations that provided an opportunity for rich language interactions were inhibited because of restrictions on the level of noise allowed in the cafeteria and teachers' strong beliefs that the children needed to eat well at mealtimes because of poor nutrition at home.

(4) How can the instructional intervention be adapted to achieve the pedagogical goal more effectively and efficiently and in a way that is appealing and engaging to all stakeholders? To address this question, iterative cycles of data collection and analysis are followed by data-driven instructional adaptations and more data collection in order to determine if the adaptations advance the intervention's effectiveness, efficiency and appeal. In our study, teachers discontinued their use of a timer used to restrict children's talk during the beginning of mealtimes, and they made efforts to stop discouraging children's conversations during mealtimes. Nonetheless, the school-wide policy of restricting the noise level in the cafeteria, basically prohibiting conversations of all students during lunchtime, was beyond the control of the preschool teachers and the intervention. That restriction illustrates how the socio-cultural milieu and teachers' and administrators' beliefs and constraints may limit the viability of an intervention and possible adaptations of it. Such factors are rarely revealed in quantitative studies and if revealed in qualitative studies, rarely are they addressed.

(5) What unanticipated positive and negative effects does the instructional intervention produce? Because an instructional intervention can produce important unanticipated consequences, data addressing this possibility are collected and analysed. For example, the purpose of our study was to increase language interactions between the teachers and children in order to facilitate children's oral language skills. Logically, these interactions would help the teachers to better understand the lives of the children in their class. However, what was 
not anticipated is the prominent role it played in our study. For example, we discovered that several children were witnessing family violence and were suspected of being sexually abused. Although disturbing, this example illustrates the depth of understanding, revealed by this methodology, that is unlikely to be revealed by more conventional methodologies.

(6) Has the instructional environment changed as a result of the intervention? This question reflects the ecological orientation of a formative experiment and the possibility that the instructional interventions might positively transform the educational environment of the classroom or the perspectives of the participants beyond the intervention being studied. To address that possibility, we collected and analysed data during children's times for independent play or 'free play', a time during the day that we did specifically ask teachers to attend to their interactions with children. Although we believed teachers' language interactions might change during free play, we did not observe any changes. However, informal and more structured interviews with the teachers indicated that they believed that they were more sensitive to the children's needs throughout the school day and that they provided examples, even during free play, of their growing awareness of children's vocabulary knowledge.

\section{New metaphors for early childhood research}

Metaphors fundamentally shape our understandings of the world and how we act in it (Lakoff \& Johnson, 1980). Metaphors guide early childhood researchers too and thus the way research is conceptualised, conducted and reported. For example, for early childhood researchers who conduct conventional experimental studies and the methods adopted from the hard sciences, the dominant metaphor is the laboratory. However, treating early childhood classrooms as laboratories denies the realities under which early childhood education occurs and the complex interacting factors with which teachers must contend. Although conventional experiments may help the field to identify instructional interventions that are effective on average and perhaps provide guidance for large-scale policy decisions, they do not provide data that are directly useful to practitioners who must manage that complexity. Nor do such experiments contribute to the development of pedagogical theories grounded in authentic practice.

Naturalistic approaches to research are also guided by metaphors. The lens through which extensive and deeply analysed observational data are gathered is perhaps the most dominant metaphor. Other metaphors include research as jazz or as rhizome (Oldfather \& West, 1994). These approaches reveal the often subtle underlying socio-cultural dynamics of classrooms and instruction and raise consciousness about important assumptions, interactions and ideologies that influence instruction and its outcomes. However, these approaches are less invested in making specific recommendations about how data and conclusions might inform instructional practice.

Two metaphors capture the essence of formative and design experiments and have been used extensively by those interested in this approach. The first is engineering, which captures the grounding of this approach in applying and developing theory in the context of seeking workable solutions to specific problems or achieving specific goals. The engineering metaphor is echoed in Stokes' (1997) argument that the distinction between basic and applied research is historically a false dichotomy. 
Pasteur, his prime example, developed much basic theoretical understanding that led to the field of microbiology in the context of his efforts to preserve food. Sloane and Gorard (2003) have pointed out that in the field of education there is no equivalent to engineering science that is prominent in other fields.

The second metaphor is ecology. Formative and design experiments approach classrooms as complex ecologies that education researchers must humbly acknowledge and respect. The validity of an investigation is seen in how authentically an intervention is studied within an existing ecology (ecological validity) and whether it can produce desirable consequences (consequential validity, see Messick, 1992) within that ecology.

We believe that one of the significant contributions of formative and design experiments is that this approach promotes a consideration of issues underlying these two metaphors. We hope that these metaphors will lead many early childhood researchers to re-examine the strengths and limitations of their preferred methodologies particularly in relation to the realities of practice and how those methodologies widen or narrow the gap between research and practice. And, we hope that such an examination will lead them to make room in the methodological landscape for formative and design experiments as a viable and useful approach that complements and extends the reach of more conventional methodologies.

\section{Notes on contributors}

Barbara A. Bradley is an assistant professor in the Department of Curriculum and Teaching at the University of Kansas in the USA. She teaches courses on emergent literacy and beginning reading. Her research interests include early literacy, teacher-child language interactions and book sharing.

David Reinking is the Eugene T. Moore professor of teacher education at Clemson University in the USA. He has served as editor of the Journal of Literacy Research (19952001) and co-editor of Reading Research Quarterly (2001-2007). His research employs formative experiments to determine how digital technologies can be integrated into classroom instruction.

\section{References}

Ball, D.L., \& Forzani, F.M. (2007). What makes education 'research educational'? Educational Researcher, 36(9), 529-540.

Barnett, W.S. (1995). Long-term effects of early childhood programs on cognitive and school outcomes. Future of Children, 5, 25-50.

Beck, I.L., \& McKeown, M.G. (2001). Text talk: Capturing the benefits of reading-aloud experiences for young children. Reading Teacher, 55, 10-20.

Bradley, B.A., \& Reinking, D. (in press). A formative experiment to enhance language interactions in a preschool classroom. Journal of Early Childhood Literacy.

Bronfenbrenner, U. (1979). The ecology of human development. Cambridge, MA: Harvard University Press.

Brown, A.L. (1992). Design experiments: Theoretical and methodological challenges in creating complex interventions in classroom settings. Journal of the Learning Sciences, 2, $141-178$.

Burchinal, M.R., Cryer, D., Clifford, R.M., \& Howes, C. (2002). Caregiver training and classroom quality in child care centers. Applied Developmental Science, 6, 2-11.

Cady, J.M., Schaak Distad, L., \& Germundsen, R.A. (1998). Reflective practice groups in teacher induction: Building professional community via experiential knowledge. Education, 118, 459-470. 
Cherryholmes, C.H. (1993). Reading research. Journal of Curriculum Studies, 25, 1-32.

Clifford, R.M., Barbarin, O., Chang, F., Early, D.M., Bryant, D., Howes, C., et al. (2005). What is pre-kindergarten? Characteristics of public pre-kindergarten programs. Applied Developmental Science, 9, 126-143.

Cobb, P., Confrey, J., diSessa, A., Lehrer, R., \& Schauble, L. (2003). Design experiments in educational research. Educational Researcher, 32, 9-13.

Cole, A.L., \& Knowles, J.G. (1993). Teacher development partnership research: A focus on methods and issues. American Educational Research Journal, 30, 473-495.

Cote, L.R. (2001). Language opportunities during mealtimes in preschool classroom. In D.K. Dickinson \& P.O. Tabors (Eds.), Beginning literacy with language (pp. 205-222). Baltimore: Paul H. Brookes.

Dickinson, D.K., \& Smith, M.W. (1994). Long-term effects of preschool teachers' book readings on low-income children's vocabulary and story comprehension. Reading Research Quarterly, 29, 104-122.

Dickinson, D.K., \& Tabors, P. (2001). Beginning literacy with language. Baltimore: Paul H. Brookes.

Dillon, D.R., O’Brien, D.G., \& Heilman, E.E. (2000). Literacy research in the next millennium: From paradigms to pragmatism and practicality. Reading Research Quarterly, 35, 10-26.

Dunn, L. (1993). Proximal and distal features of day care quality and children's development. Early Childhood Research Quarterly, 8, 167-192.

Ebel, R. (1982). The future of educational research. Educational Researcher, 22, 18-19.

Edwards, S. (2007). From developmental-constructivism to sociocultural theory and practice: An expansive analysis of teachers' professional learning in early childhood education. Journal of Early Childhood Research, 5, 83-106.

Eisenhart, M., \& Borko, H. (1993). Designing classroom research: Themes, issues, and struggles. Boston: Allyn \& Bacon.

Firestone, W.A. (1993). Alternative arguments for generalizing from data as applied to qualitative research. Educational Researcher, 22(4), 16-23.

Girolametto, L., Weitzman, E., van Lieshout, R., \& Duff, D. (2000). Directiveness in teachers' language input to toddlers and preschoolers in day care. Journal of Speech, Language, and Hearing Research, 43, 1101-1114.

Gormley, W.T., Gayer, T., Phillips, D., \& Dawson, B. (2005). The effects of universal pre-K on cognitive development. Developmental Psychology, 41, 872-884.

Gravemeijer, K., \& Cobb, P. (2006). Design research from a learning design perspective. In J. van den Akker, K. Gravemeijer, S. Mckenney, \& N. Nieveen (Eds.), Educational design research (pp. 17-51). New York: Routledge.

Helburn, S.W. (1995). Cost, quality, and child outcomes in childcare centers. Denver, CO: Center for Research in Economics and Social Policy, University of Colorado.

Hughes, M., \& Westgate, D. (1997). Assistants as talk-partners in early-years classrooms: Some issues of support and development. Education Review, 49, 5-12.

Ivey, G., \& Broaddus, K. (2007). A formative experiment investigating literacy engagement among adolescent Latina/o students beginning to read, write, and speak English. Reading Research Quarterly, 42, 512-545.

Jacob, E. (1992). Culture, context, and cognition. In M.D. Lecompte, W.L. Millroy, \& J. Preissle (Eds.), The handbook of qualitative research in education (pp. 293-335). San Diego, CA: Academic Press.

Johnson, R.B., \& Onwuegbuzie, A.J. (2004). Mixed methods research: A research paradigm whose time has come. Educational Researcher, 33, 14-36.

Kelly, A.E., Lesh, R.A., \& Baek, J.Y. (Eds.). (2008). Handbook of design research methods in education: Innovations in science, technology, engineering, and mathematics learning and teaching. New York: Routledge.

Kirp, D.L. (2007). The sandbox investment: The preschool movement and kids-first policies. Cambridge, MA: Harvard University Press.

Klein, N.K., \& Gilkerson, L. (2000). Personnel preparation for early intervention programs. In J.P. Shonkoff \& S.J. Meisels (Eds.), Handbook of early childhood intervention (2nd ed., pp. 454-483). New York: Cambridge University Press.

Kontos, S., \& Wilcox-Herzog, A. (1997). Teachers' interactions with children: Why are they so important? Young Children, 52, 4-12. 
Kowalski, K., Pretti-Frontczak, K., \& Johnson, J. (2001). Preschool teachers' beliefs concerning the importance of various developmental skills and abilities. Journal of Research in Childhood Education, 16, 5-14.

Lagemann, E.C. (2000). An elusive science: The troubling history of education research. Chicago: University of Chicago Press.

Lakoff, G., \& Johnson, M. (1980). Metaphors we live by. Chicago: University of Chicago Press.

Lenski, S.D. (2001). Intertextual connections during discussions about literature. Reading Psychology, 22, 313-335.

Li, S., Marquart, J.M., \& Zercher, C. (2000). Conceptual issues and analytic strategies in mixed-method studies of preschool inclusion. Journal of Early Intervention, 23, 116-132.

Malouf, D., \& Schiller, E. (1995). Practice and research in special education. Exceptional Children, 61, 414-424.

Messick, S. (1992). The interplay of evidence and consequences in the validation of performance assessments. Educational Researcher, 23, 13-23.

Moll, L., \& Diaz, S. (1987). Change as the goal of educational research. Anthropology and Education Quarterly, 18, 300-311.

Neuman, S.B. (1999). Books make a difference: A study of access to literacy. Reading Research Quarterly, 34, 286-311.

NICHD (Early Childhood Care Research Network). (2005). Pathways to reading: The role of oral language in the transition to reading. Developmental Psychology, 41, 428-442.

Oldfather, P., \& West, J. (1994). Qualitative research as jazz. Educational Researcher, 23, 22-26.

Pressley, M., Graham, S., \& Harris, K. (2006). The state of educational intervention research as viewed through the lens of literacy intervention. British Journal of Educational Psychology, 76, 1-19.

Raver, C.C., Jones, S.M., Li-Grining, C.P., Metzger, M., Champion, K.M., \& Sardin, L. (2008). Improved preschool classroom processes: Preliminary findings from a randomized trial implemented in Head Start settings. Early Childhood Research Quarterly, 23, 10-26.

Reinking, D., \& Bradley, B.A. (2004). Connecting research and practice using formative and design experiments. In N.K. Duke \& M.H. Mallette (Eds.), Literacy research methodologies (pp. 149-169). New York: Guilford.

Reinking, D., \& Bradley, B.A. (2008). Formative and design experiments: Approaches to language and literacy research. New York: Teachers College Press.

Reinking, D., \& Watkins, J. (2000). A formative experiment investigating the use of multimedia book reviews to increase elementary students independent reading. Reading Research Quarterly, 35, 384-419.

Ryan, S. (2004). Message in a model: Teachers' responses to a court-ordered mandate for curriculum reform. Educational Policy, 18, 661-685.

Schwartz, I.S., \& Carta, J. (1996). Examining the use of recommended language intervention practices in early childhood special education. Topics in Early Childhood Special Education, 16, 251-273.

Schön, D. (1987). Educating the reflective practitioner. San Francisco: Jossey-Bass.

Sloane, F.C., \& Gorard, S. (2003). Exploring modeling aspects of design experiments. Educational Researcher, 32, 29-31.

Snow, C.E. (1983). Literacy and language: Relationships during the preschool year. Harvard Educational Review, 53(2), 165-189.

Snow, C.E. (1991). The theoretical basis for relationships between language and literacy in development. Journal of Research in Childhood Education, 6, 5-10.

Sparks-Langer, G.M., \& Colton, A.B. (1991). Synthesis of research on teachers' reflective thinking. Educational Leadership, 48(8), 37-44.

Stokes, D.E. (1997). Pasteurs's quadrant. Washington, DC: Brookings Institution Press.

Storch, S.A., \& Whitehurst, G.J. (2002). Oral language and code-related precursors to reading: Evidence from a longitudinal structural model. Developmental Psychology, 38, 934-947.

Takanishi, R., \& Bogard, K.L. (2007). Effective educational programs for young children: What we need to know. Child Development Perspectives, 1, 40-45.

Tizard, B., \& Hughes, M. (1984). Young children learning. London: Fontana. 
van den Akker, J., Gravemeijer, K., McKenney, S., \& Nieveen, N. (Eds.). (2006). Educational research design. London: Routledge.

Wasik, B.A., Bond, M.A., \& Hindman, A. (2006). The effects of a language and literacy intervention on Head Start children and teachers. Journal of Educational Psychology, 98, 63-74.

Whitebrook, M.C., Howes, C., \& Phillips, D. (1989). The national child care staffing study: Who cares? Child care teachers and the quality of care in America (Final Report). Oakland, CA: Child Care Employee Project. 